\title{
Article \\ Influence of Host-Related Factors and Exposure to Mosquito Bites on the Dynamics of Antibody Response to Plasmodium falciparum Antigens
}

\author{
Kakou G. Aka ${ }^{1,2}{ }^{(D}$, Serge S. Yao ${ }^{3}$, Eric A. Gbessi ${ }^{3}$, Akré M. Adja ${ }^{1,4}{ }^{\text {, Vincent Corbel }}{ }^{2}$, Alphonsine A. Koffi ${ }^{1}$, \\ Christophe Rogier ${ }^{5,6}$, Serge B. Assi ${ }^{1,7}$, Offianan A. Toure ${ }^{3}$, Franck Remoue ${ }^{1,2}$ (D) and Anne Poinsignon 1,2,*(D) \\ 1 Institut Pierre Richet/Institut National de Santé Publique, Bouaké, Côte d'Ivoire; \\ ghislain.aka@gmail.com (K.G.A.); adjamaurice@yahoo.fr (A.M.A.); koffi_alphonsine@yahoo.fr (A.A.K.); \\ assisergi@yahoo.fr (S.B.A.); franck.remoue@ird.fr (F.R.) \\ 2 MIVEGEC, University of Montpellier, IRD, CNRS, 34000 Montpellier, France; vincent.corbel@ird.fr \\ 3 Unité de Paludologie, Institut Pasteur de Côte d'Ivoire, Abidjan 01 BP 490, Côte d'Ivoire; \\ yaoserstephane@gmail.com (S.S.Y.); ericadji@yahoo.fr (E.A.G.); andre_offianan@yahoo.fr (O.A.T.) \\ 4 UFR Biosciences, University Felix Houphouet Boigny, Abidjan 01 BP V34, Côte d'Ivoire \\ 5 Primum Vitare!, Paris, France; christophe.rogier@gmail.com \\ 6 Institut Pasteur de Madagascar, Antananarivo 101, Madagascar \\ 7 Programme National de Lutte contre le Paludisme, Abidjan, Côte d'Ivoire \\ * Correspondence: anne.poinsignon@ird.fr
}

check for updates

Citation: Aka, K.G.; Yao, S.S.; Gbessi, E.A.; Adja, A.M.; Corbel, V.; Koffi,

A.A.; Rogier, C.; Assi, S.B.; Toure,

O.A.; Remoue, F.; et al. Influence of

Host-Related Factors and Exposure to

Mosquito Bites on the Dynamics of Antibody Response to Plasmodium falciparum Antigens. Trop. Med. Infect. Dis. 2021, 6, 185. https://doi.org/ $10.3390 /$ tropicalmed6040185

Academic Editor: Paul Horrocks

Received: 9 September 2021

Accepted: 11 October 2021

Published: 18 October 2021

Publisher's Note: MDPI stays neutral with regard to jurisdictional claims in published maps and institutional affiliations.

Copyright: (c) 2021 by the authors. Licensee MDPI, Basel, Switzerland. This article is an open access article distributed under the terms and conditions of the Creative Commons Attribution (CC BY) license (https:// creativecommons.org/licenses/by/ $4.0 /)$.
Abstract: Humoral immunity to Plasmodium falciparum is acquired after repeated infections, and can lead to clinical protection. This study aimed to evaluate how human-, parasite-, and environmentrelated determinants can modulate the dynamics of IgG responses to Plasmodium falciparum after an infection. Individuals ( $n=68$, average age $=8.2$ years) with uncomplicated malaria were treated with ACT and followed up for 42 days. IgG responses to P. falciparum merozoite antigens (PfMSP1, PfMSP3, PfAMA1, PfGLURP-R0), to whole schizont extract (PfSchz), and to Anopheles gSG6-P1 and Aedes Nterm-34 kDa salivary peptides were measured. Regression analyses were used to identify factors that influence the dynamics of IgG response to P. falciparum antigen between D0 and D42, including demographic and biological factors and the level of exposure to mosquito bites. The dynamics of IgG response to $P$. falciparum differed according to the antigen. According to multivariate analysis, IgG responses to $P f S c h z$ and to $P f G L U R P-R 0$ appear to be affected by exposure to Aedes saliva and are associated with age, parasite density, and anti-Plasmodium pre-existing immune response at study inclusion. The present work shows that human exposure to Aedes saliva may contribute, in addition to other factors, to the regulation of anti-Plasmodium immune responses during a natural infection.

Keywords: Plasmodium falciparum; malaria; Anopheles; Aedes; humoral acquired immunity; saliva; immunomodulation; exposure

\section{Introduction}

In malaria-endemic settings, human populations acquire humoral immunity to Plasmodium falciparum ( $P$. falciparum) after repeated infections, which can lead to clinical protection in reducing blood-stage parasitemia and life-threatening symptoms. Natural protective acquired immunity was first highlighted in studies where passive transfer of purified immunoglobulin G (IgG) obtained from malaria-immune adults successfully reduced Plasmodium parasitemia in children [1,2]. Although the targets and mechanisms of this protective immunity are not completely understood, several studies suggest that high antibody $(\mathrm{Ab})$ levels against certain blood-stage merozoite antigens play an important role in clinical protection, making these Plasmodium antigens potential anti-malaria vaccine candidates. Clinical protective immunity is dependent on high concentrations of IgG as 
well as of cytophilic IgG1 and IgG3 Abs to blood-stage antigens, including apical membrane antigen 1 (PfAMA1) [3,4], merozoite surface protein 1 and 3 (PfMSP1, Pf MSP3) [5-7], and glutamate-rich protein (PfGLURP-R0) [8]. However, recent study has found greater associations with protection when measuring functional antibodies that fix complement than antibodies that inhibit growth [9]. Longitudinal immunological studies have reported anti-P. falciparum $\mathrm{Ab}$ responses increase and peak within 1-2 weeks after a malaria infection, and then generally decline rapidly, suggesting a short-lived duration of circulating IgG to merozoite antigens (2-3 weeks) [10,11]. On the other hand, $\mathrm{Ab}$ responses may last for many years, and this persistence was positively associated with age, as a reflection of cumulative exposure to Plasmodium infections [12,13]. Immune responses are complex traits and may be influenced by different determinants in addition to intrinsic Ab half-life. A deeper understanding of host- and parasite-related factors, as well as of environmental factors, modulating the antigen-specific Ab response dynamics after a Plasmodium infection is important in selecting which antigens are valuable for the development of serological surveillance tools or anti-malaria vaccines.

Age, genetic factors, parasite density, previous exposure to Plasmodium, pathogen coinfection, and nutritional status are known to influence anti-Plasmodium Ab responses [14-17]. Environmental factors may also influence vertebrate immunity activity; annual seasonality is found to be an important environmental factor influencing cytokine production [18]. Immunomodulatory components of mosquito saliva are an interesting but often overlooked environmental factor.

In malaria-endemic areas, human populations are repeatedly exposed to salivary components of blood-feeding mosquitoes that possess a variety of pharmacologically active biomolecules with anti-hemostatic, anti-inflammatory, and immunomodulatory properties [19]. Mosquito immunomodulatory salivary proteins act both on innate and adaptive immunity [20], and studies suggested that T-cell populations are particularly susceptible to the effects of mosquito saliva [21,22]. T- and B-cell proliferation seems to be inhibited in a dose-dependent manner. High concentrations of saliva or repeated pre-exposure to mosquito saliva create an immunosuppressed environment, whereas decreasing saliva concentrations, instead, modulate the Th1/Th2 immune response [23-26]. A study examining immune responses to the bites of An. stephensi reported mast cell degranulation leading to local fluid and neutrophil influx and lymph node hyperplasia as a result of the recruitment of lymphocytes, dendritic cells, and monocytes [27]. Anopheles saliva also induced IL-10 in draining lymph nodes and downregulated antigen-specific T-cell responses [21]. Repeated pre-exposure to Anopheles bites also seems to skew the response towards that of the Th1 phenotype and to protect against Plasmodium yoelii infection [28], but these results are controversial [29,30]. Thus, human immune responses modulated by mosquito saliva are significant and complex in altering the frequencies of several immune cell populations and of cytokine production in multiple tissues, and can last for several days in the skin and at the systemic level [26].

However, there is presently only a limited understanding of the immune microenvironment initiated by arthropod salivary components in the vertebrate host and their role in the modulation of specific immunity against pathogens. A limited number of experimental studies showed that mice exposed to arthropod bites had a down-regulated antigen-specific immune response compared with naïve mice [21,31]. Studies in human populations living in malaria-endemic areas showed that acquired anti-Plasmodium $\mathrm{Ab}$ responses differed in children with varying exposure to Anopheles bites. A difference in the cytophilic Ab response to Plasmodium according to the intensity of exposure to Anopheles bites was reported, with a down-regulated IgG1 level seen in children with higher exposure, while IgG3 levels were similar in children with low or high exposure to Anopheles bites [32]. More recently, a study suggested that, in addition to other factors, Anopheles saliva may also down-modulate the anti-PfMSP1 IgG, IgG1, and IgG3 immunity [33].

The major aims of the present study were to explore the key human-, parasite-, and environment-related factors that modulate anti-Plasmodium falciparum Ab dynamics after 
an infection. To address these aims, individuals with an uncomplicated clinical malaria attack visiting a health center in Bouaké (Côte d'Ivoire) were enrolled in the study, treated with artemisinin-based combination therapy (ACT), and followed up for 42 days. The variation in the anti-Plasmodium IgG response during follow-up and the identification of factors that may influence its dynamics were assessed through univariate and multivariate regression analysis. Plasmodium merozoite-stage specific antigens (PfMSP1, PfMSP3, PfAMA1, and PfGLURP-R0) and schizont extract (PfSchz) were selected for their differences in immunogenicity and persistence [34,35] and for their potential in an advanced malaria vaccine [36].

The intensity of Anopheles and Aedes exposure was assessed at the individual level by evaluating the IgG response to the Anopheles gSG6-P1 and Aedes Nterm-34-kDa salivary peptides. During the last decade, these serological biomarkers were developed and aimed at evaluating the level of exposure to mosquito bites [37,38]. Specific human IgG against salivary peptides from Anopheles (gSG6-P1) and Aedes (Nterm-34 kDa) represents a proxy of human exposure to Anopheles and Aedes bites and is a reliable tool for assessing the spatial and temporal heterogeneity of exposure at the individual level $[39,40]$.

\section{Materials and Methods}

\subsection{Ethics Statement}

The present study followed the ethical principles recommended by the Edinburgh revision of the Declaration of Helsinki and was approved by the Ethics Committee of the Côte d'Ivoire Ministry of Health (June 2014; No. 41/MSLS/CNER-dkn). Site leaders provided prior permission to survey on each site and written informed consent of all parents or guardians of children who participated in the study was obtained before inclusion.

\subsection{Study Area}

The study was conducted in Dar-es-Salam, a neighborhood of Bouaké city located in the center of Côte d'Ivoire, from April to June 2016. The local climate and malaria epidemiology have been previously described $[33,41]$. The area has intense malaria transmission and P. falciparum accounts for more than 95\% of all human malaria infections [42], with $A n$. gambiae s.l. being the major vector $[43,44]$. The climate is tropical humid with two seasons: The dry season runs from November through March, and the rainy season from April to October. Malaria transmission is perennial with seasonal upsurges during the rainy season.

\subsection{Study Design, Procedure, and Sample Collection}

The study was carried out during a clinical trial that aimed to assess the in vivo efficacy of artemisinin-based anti-malarial combination therapies. Details of the study, clinical procedures, and drug administration are described elsewhere [45]. Briefly, patients ( $n=120$, age $>6$ months) with uncomplicated malaria and monospecific $P$. falciparum infestation confirmed by microscopy (parasite density between 2000 and 200,000 asexual parasites / $\mu \mathrm{L}$ of blood), axillary temperature of $\geq 37.5^{\circ} \mathrm{C}$, or a history of fever over the past $24 \mathrm{~h}$, with body weight $\geq 5 \mathrm{~kg}$, and who were able to take oral medications and follow study procedures were included in the study. All participants were treated with artemisinin-based combination therapies - artesunate + amodiaquine (AS + AQ) or artemether + lumefantrine (AL) - for 3 days (day 0 (D0), D1, D2), and then visited every week (between D7 and D42). Blood samples were collected repeatedly on D0, D3, and weekly from D7 to the end point of the follow-up (D42), for thick and thin blood smears. Dried blood spots (DBS) on Whatman $3 \mathrm{MM}$ filter paper were collected on D0 and D42, air-dried and stored in plastic bags at $+4{ }^{\circ} \mathrm{C}$ until immunological analysis. Thick blood smears were fixed and stained with $10 \%$ Giemsa and read double-blind by two certified microscopists; discordant readings were re-examined by a third qualified independent microscopist. Asexual parasite densities were counted against 200 microscope fields assuming 8000 white blood cells per microliter. A blood smear was considered negative if no parasites were observed. 
The present study was carried out with the blood samples collected on D0 and D42 from 68 individuals out of the initial 120, including only individuals not lost to follow-up, without therapeutic failure, not becoming re-infected during the follow-up, and whose blood samples on D0 and D42 were available.

\subsection{Parasite and Salivary Antigens}

The Plasmodium merozoite-stage specific antigens (PfMSP1, PfMSP3, PfAMA1, and PfGLURP-R0) were produced in recombinant form and kindly provided by collaborators. PfMSP-1p19 (Uganda-Palo-Alto strain) was expressed in a Baculovirus/insect cell system [46]; the recombinant PfAMA1 (amino-acids 25-545, FVO strain) was expressed in Pichia pastoris [47]; and PfMSP3 (amino acids 212-380, F32 strain) and PfGLURP-R0 (amino acids 25-514, F32 strain) were expressed in Escherichia coli $[48,49]$. The schizont extracts (PfSchz) were produced from P. falciparum cultures (strain 07/03, [50]). The gSG6-P1 and Nterm-34 kDa salivary peptides [51,52] were synthesized and purified (purity: $>95 \%$ ) by Genepep (St-Jean de Vedas, France). Peptides were shipped in lyophilized form and then resuspended separately in milliQ water and stored in aliquots at $-20{ }^{\circ} \mathrm{C}$ until use.

2.5. Enzyme-Linked Immunosorbent Assay: Human Antibody Response to P. falciparum Antigens, gSG6-P1 and Nterm-34 kDa Salivary Peptides

Standardized dried blood spots (diameter: $1 \mathrm{~cm}$ ) of each participant at two time points (D0 and D42) were eluted each in $350 \mu \mathrm{L}$ phosphate buffered saline containing $0.1 \%$ Tween $20\left(0.1 \%\right.$ PBST) at $+4{ }^{\circ} \mathrm{C}$ for $48 \mathrm{~h}$. Human IgG levels against the gSG6-P1, Nterm$34 \mathrm{kDa}$, PfSchz, PfAMA1, PfMSP1, PfMSP3, and PfGLURP-R0 antigens were measured by enzyme-linked immunosorbent assay (ELISA).

Subsequently, 96-well Maxisorp micro-assay plates (Nunc, Roskilde, Denmark) were coated overnight at $4{ }^{\circ} \mathrm{C}$ at a dilution of $1 / 1200$ for PfSchz, $1 \mu \mathrm{g} / \mathrm{mL}$ for PfAMA1 and PfMSP1, and $2 \mu \mathrm{g} / \mathrm{mL}$ for PfMSP3 and PfGLURP-R0. Plates were blocked with 5\% skimmed milk powder $(w / v)$ in $0.1 \%$ PBST for $1 \mathrm{~h}$ at room temperature. Individual eluates diluted in buffer ( $1 \%$ milk powder in $0.1 \%$ PBST) were added for incubation $(2 \mathrm{~h}$ at room temperature) at a final dilution of 1/10 for PfSchz, 1/50 for PfMSP3 and PfGLURP-R0, and 1/200 for PfAMA1 and PfMSP1. Plates were washed three times between each step with washing buffer (0.1\% PBST). HRP-conjugated goat anti-human IgG (Frederick, USA), diluted at 1/1000 for PfMSP3, 1/2500 for PfGLURP-R0, and 1/5000 for all the other $P$. falciparum antigens, was added, and samples were incubated for $1 \mathrm{~h}$ at room temperature. After four further washes, TMB (Kementec, Taastrup, Denmark) was used as a substrate and the reaction was stopped by adding $0.2 \mathrm{M} \mathrm{H}_{2} \mathrm{SO}_{4}(100 \mu \mathrm{L} /$ well). The optical density (OD) was read after $30 \mathrm{~min}$ at $450 \mathrm{~nm}$. All samples were tested in duplicate, and if there was a discrepancy of greater than $25 \%$ between duplicates, the sample was retested. Individual results $(\triangle \mathrm{OD})$ are expressed as: $\triangle \mathrm{OD}=\mathrm{ODx}-\mathrm{ODn}$, where ODx represents the mean of the individual OD value in both wells with $P$. falciparum antigen and ODn the individual OD value for each eluate without antigen. A pool of positive hyperimmune serum collected from adult residents in a malaria-endemic area [32] was included on each plate to allow for standardization of day-to-day and plate-to-plate variation. Standard curves were established using human purified IgG protein (The Binding Site, Saint-Egreve, France) to convert $\triangle \mathrm{OD}$ values for each sample into IgG concentrations (CPf in $\mathrm{ng} / \mathrm{mL}$ ). Each plate included a calibration (standard) curve with eight doubling dilutions of human purified IgG (3.12-400 ng/mL for schizont extract; $0.78-100 \mathrm{ng} / \mathrm{mL}$ for PfAMA1 and PfMSP1; 0.58-75 ng/mL for PfGLURP-R0 and Pf MSP3). To construct the standard curve, we plotted the OD values at the corresponding known concentrations of purified human IgG, and then defined the standard curve using linear regression analysis. The IgG concentration of blood samples from participants were predicted from this equation based on the OD value. European nonimmune individual sera ( $n=16$, France) served as negative controls to determine the cut-off value for seropositivity for each Plasmodium antigen, defined as mean OD plus three standard deviations (mean[ $\Delta$ ODneg] +3 SDneg). 
Serology testing of human exposure to mosquito salivary antigens (Nterm-34 kDa and gSG6-P1) was carried out by ELISA as described in [33] but with some modifications. Sera were incubated in duplicate wells at $4{ }^{\circ} \mathrm{C}$ overnight at a dilution of $1 / 40$ in $0.1 \%$ PBST, mouse biotinylated Ab to human IgG (BD Pharmingen, San Diego CA, USA) was incubated at a dilution of $1 / 2000$ in $1 \%$ PBST, and streptavidin biotin peroxidase was then added $\left(1 / 1000 ; 1 \mathrm{~h}\right.$ at $\left.37^{\circ} \mathrm{C}\right)$. Individual results are expressed as the $\Delta \mathrm{OD}$ value: $\Delta \mathrm{OD}=\mathrm{ODx}-\mathrm{ODn}$, as mentioned above. Specific anti-gSG6-P1 and Nterm-34 kDa IgG levels were also assessed in European individuals ( $n=16$, France) to calculate the cut-off value for seropositivity for mosquito exposure (mean[ $\Delta \mathrm{ODneg}]+3 \mathrm{SDneg}$ ).

\subsection{Immunological Data Analysis}

The dynamics of specific IgG responses to $P$. falciparum antigens were investigated for each individual during the follow-up. Results are expressed as a $\triangle C P f$ D42-D0 value, calculated according to the formula $\triangle \mathrm{CPf}$ D42-D0 $=\mathrm{CP} f_{\mathrm{D} 42}-\mathrm{CP} f_{\mathrm{D} 0}$.

In the present study, we were interested in the effect of mosquito exposure on the evolution of humoral immunity to Plasmodium following an infection. Assuming that antisalivary peptide IgG responses are transient and wane within a few weeks [53], evaluating the exposure on D42 may reflect exposure since current infection. Thus, individuals were separated into groups of exposure according to their IgG responses to the gSG6P1 and Nterm-34 kDa peptides on D42. The mean values of the IgG responses to the salivary peptides were determined as the thresholds to define two groups of participants with different exposures (single-genus exposure) to Anopheles (lower exposure [LE $\left.\mathrm{LEno}_{\mathrm{An}}\right]<$ $\Delta \mathrm{OD}_{\mathrm{gSG}}$-P1 $=1.41<$ higher exposure $\left.\left[\mathrm{HE}_{\text {Ano }}\right]\right)$ and two groups with different exposures to Aedes (lower exposure $\left[\mathrm{LE}_{\mathrm{Ae}}\right]<\Delta \mathrm{OD}_{\mathrm{Nterm}-34 \mathrm{kDa}}=1.10<$ higher exposure $\left[\mathrm{HE}_{\mathrm{Ae}}\right]$ ). Then, from these four groups of single-genus exposure, three exposure groups (combined Anopheles and Aedes exposure) were defined as follows: individuals with lower exposure to both Anopheles and Aedes were included in group E2 (Low); individuals with higher exposure to both Anopheles and Aedes were included in group E4 (High); and individuals from the lower-exposure group to one mosquito genus and from the higher-exposure group to the other mosquito genus were included in group E3 (Intermediate).

\subsection{Covariates}

Individual characteristics were analyzed as categorical (gender, ACT treatment) or continuous (age, weight, hemoglobin) variables to estimate their influence on the dynamics of $\mathrm{Ab}$ responses. Parasite density and immunologic responses (anti-Plasmodium IgG concentration on D0 and anti-salivary peptide IgG levels on D42) were analyzed as continuous variables in the linear analyses.

\subsection{Statistical Analysis}

Data generated from assays in the form of $\triangle \mathrm{OD}$ values were entered into Microsoft Excel worksheets, and raw $\triangle \mathrm{OD}$ representing IgG responses to $P$. falciparum were converted into concentration $(\mathrm{CPf} \mathrm{ng} / \mathrm{mL}$ ). All statistical analyses were conducted in R (Version 3.3.3; R Core Team, Vienna, Austria) with "tidyverse lattice" and "moment" packages. Figures were generated in R using the "ggplot2" package. A cut-off for seropositivity was determined for each antigen, and individuals were categorized as seropositive if their $A b$ response was above the cut-off value.

As immunologic data were not normally distributed, nonparametric tests were used for statistical analyses. The Wilcoxon signed-rank test was used to examine individual differences in $\mathrm{Ab}$ during the follow-up, the Mann-Whitney $\mathrm{U}$ (Wilcoxon rank-sum) test was run for comparison of Ab levels between two independent groups, and the KruskalWallis test was used for differences among more than two groups. The association between two continuous variables was determined through Spearman's correlation coefficient (Spearman's rho, and $p$ values are reported). 
Multivariate linear regression models were then used for all covariates with a $p$-value of $<0.20$ in univariate analysis. Final models were adjusted by backward selection and by removing non-significant variables of $p>0.05$. Maximum likelihood method tests were used to identify the best-fitting models according to the Akaike information criterion (AIC) value. All differences were considered significant at $p<0.05$.

\section{Results}

\subsection{Population Baseline Characteristics}

A total of 68 individuals were included in this study: 41 (60.3\%) females and $27(39.7 \%)$ males with an average age of 8.2 years (95\% confidence interval (CI), (6.9-9.5)). The age structure of the population was 22 children $\leq 5$ years, 24 children between 6 and 9 years of age, and 22 participants $\geq 10$ years. The overall mean $P$. falciparum density at study inclusion was 54,965 parasites $/ \mu \mathrm{L}(95 \% \mathrm{CI},(42,673-70,798))$, and there was no difference in parasite density between age groups $(p=0.369)$. The mean hemoglobin $(\mathrm{Hb})$ concentration was $12.38 \mathrm{~g} / \mathrm{dL}$ and $11.82 \mathrm{~g} / \mathrm{dL}$, respectively, on D0 and D42 ( $p=0.665)$.

\subsection{Human IgG Response to P. falciparum and Mosquito Salivary Antigens during Follow-Up}

The concentration levels of IgG to P. falciparum antigens (ng/mL) and to mosquito salivary peptides (in OD value), as well as seroprevalence both at the time of inclusion (D0) and at the end of the follow-up (D42), are presented in Table 1.

Table 1. IgG seroprevalence and level of IgG response to Plasmodium falciparum antigens and to gSG6-P1 and Nterm-34 kDa salivary peptides on D0 and D42.

\begin{tabular}{|c|c|c|c|c|c|}
\hline & \multicolumn{2}{|c|}{ Do } & \multicolumn{2}{|c|}{ D42 } & \multirow{2}{*}{$p$ Value $^{\mathrm{b}}$} \\
\hline & IgG Prevalence a (\%) & Median (IQR) & IgG Prevalence $(\%)$ & Median (IQR) & \\
\hline PfAMA1 & 70.58 & $5.78(0.43-1.28)$ & $73.52 \%$ & $2.64(0.70-9.53)$ & 0.110 \\
\hline PfGLURP-R0 & 70.58 & $0.20(0.02-0.64)$ & $17.65 \%$ & $0.04(0-0.12)$ & $<0.001$ \\
\hline PfMSP1 & 61.76 & $1.95(0.30-25.0)$ & $51.47 \%$ & $2.27(0.40-9.65)$ & 0.541 \\
\hline PfMSP3 & 82.35 & $0.13(0-0.37)$ & $61.76 \%$ & $0.12(0-0.50)$ & 0.987 \\
\hline PfSchz & 100 & $1.15(0.78-1.76)$ & $100 \%$ & $2.09(1.31-2.85)$ & $<0.0001$ \\
\hline gSG6-P1 & 100 & $1.32(1.12-1.60)$ & $100 \%$ & $1.41(1.07-1.61)$ & 0.760 \\
\hline Nterm-34 kDa & 100 & $1.06(0.91-1.25)$ & $100 \%$ & $1.1(0.86-1.31)$ & 0.638 \\
\hline
\end{tabular}

IQR: Interquartile range. Median values of IgG concentration to $P$. falciparum antigens expressed at $10-3 \mathrm{ng} / \mu \mathrm{L}$. ${ }^{\mathrm{a}}$ European nonimmune individual sera ( $n=16$, France) served as negative controls to determine the cut-off value for seropositivity for each Plasmodium antigen, defined as mean OD plus three standard deviations (mean[ $\Delta$ ODneg] +3 SDneg). ${ }^{b} p$ value for the comparison of the antibody levels between D0 and D42 for each antigen, determined by Wilcoxon rank-sum test.

On D0, most of the individuals had a specific IgG response to $P$. falciparum antigens, ranging from $61.8 \%$ for PfMSP1 to $100 \%$ for PfSchz. For all merozoite antigens, the seroprevalence decreased during the follow-up, except for PfAMA1, for which a similar rate was noted between D0 and D42. All individuals had a specific IgG response to PfSchz at the two time points.

A wide range of anti-PfAMA1, anti-PfMSP1, and anti-PfSchz IgG concentration levels on D0 and D42 were observed in individuals, whereas other anti-Plasmodium IgG responses were much more limited. Anti-PfSchz IgG median levels increased significantly during the follow-up ( $p<0.0001)$, whereas participants had significantly lower anti-PfGLURP-R0 IgG median levels at the end of the follow-up $(p<0.001)$. No significant differences were noted in the median levels of IgG responses to PfAMA1, PfMSP1, and PfMSP3 between D0 and D42.

We also evaluated the individual level of exposure to Anopheles and Aedes bites at the two time points by assessing the IgG response to the Anopheles gSG6-P1 and Aedes Nterm-34 kDa salivary peptides. The seroprevalence of anti-salivary peptide IgG was $100 \%$ and the wide range of $\Delta \mathrm{OD}_{\mathrm{gSG} 6-\mathrm{P} 1}$ and $\Delta \mathrm{OD}_{\mathrm{Nterm}-34 \mathrm{kDa}}$ values indicated that all participants were exposed to mosquito bites, albeit at different levels of exposure. However, no differences in the IgG median levels were noted between D0 and D42 (Wilcoxon test, 
$p>0.05)$ for the two salivary antigens, indicating a similar exposure to Anopheles and Aedes bites before (exposure estimated on D0) and during the cohort follow-up (exposure estimated on D42).

\subsection{Dynamics of IgG Responses to P. falciparum According to Anopheles and Aedes Exposure}

We assessed the evolution of the concentration of IgG against $P$. falciparum antigens $\left(\triangle \mathrm{CPf} \mathrm{D42-D0}_{\mathrm{D}}\right)$ in participants according to their individual levels of exposure to Anopheles and Aedes bites. Exposure was considered first at a single-genus level (Anopheles [LE Ano $_{\text {and }}$ and $\mathrm{HE}_{\mathrm{Ano}}$ ] or Aedes [ $\left[\mathrm{LE}_{\mathrm{Ae}}\right.$ and $\left.\mathrm{HE}_{\mathrm{Ae}}\right]$ separately) and, secondly, at a combined level (Anopheles and Aedes taken together: E2 = low-, E3 = intermediate-, E4 = high-exposure groups).

First, we compared the dynamics of IgG responses to Plasmodium antigens ( $\triangle \mathrm{CPf}$ D42-D0) between the groups with lower and higher exposure to Anopheles or Aedes bites (Figure 1). The dynamics of immune responses were calculated as the concentration at D42 minus the concentration at D0, which meant that the median values close to zero showed similar response levels between the 2 time points, not zero antibodies.

Individuals who had a higher exposure to Anopheles $\left(\mathrm{HE}_{\mathrm{Ano}}\right)$ or to Aedes $\left(\mathrm{HE}_{\mathrm{Ae}}\right)$ bites exhibited a greater increase in anti-PfSchz IgG levels than those with a lower exposure ( $p=0.0029$ for Anopheles and $p=0.005$ for Aedes). No significant differences in the variation of IgG responses to merozoite antigens were noted between the two groups exposed to Anopheles or Aedes bites.

Second, we compared the dynamics of anti-Plasmodium immune responses according to the level of combined exposure to both Anopheles and Aedes bites (E2 = low, E3 = intermediate, E4 = high; Figure 2). We observed a positive association between the increase in the IgG response to PfSchz and the level of mosquito exposure during the followup. Indeed, individuals with higher exposure to Anopheles and Aedes (E4 group) had a significantly greater increase in anti-PfSchz IgG response compared with individuals from the group with intermediate exposure (E3 group, $p=0.027$ ) and from the group with lower exposure (E2 group, $p=0.0024$ ). No significant differences in the dynamics of anti-merozoite antigen IgG responses were noted between the exposure groups, with all median values close to null for any exposure group (combined exposure).

\subsection{Human-, Parasite-, and Environment-Related Factors Associated with the Evolution of Immune Responses to Plasmodium}

Univariate analyses were first performed to investigate the relationship between the individual variation in specific anti-Plasmodium IgG responses and different demographic, biological, parasitological, and environmental variables (Table 2).

Gender, hemoglobin concentration, and parasite density on D0 were not associated with any variation in IgG response to Plasmodium antigens $(p>0.05)$. The type of ACT treatment was also not associated with any variation in immune responses to Plasmodium antigens except for $\operatorname{PfMSP3}(p=0.021)$, while age and weight were associated with variations in IgG against PfSchz ( $p=0.049$ and $p=0.037$, respectively) and Pf AMA1 ( $p=0.051$ and $p=0.006$, respectively). In addition, variations in IgG against all antigens were negatively associated with the initial concentration on D0 $(p<0.002)$. We also assessed the effect of exposure to Anopheles or Aedes bites (continuous variable) on the variation in the specific anti-Plasmodium IgG responses. Only the anti-PfSchz IgG level was positively associated with the level of exposure to Anopheles $(R=0.405, p<0.001)$ and Aedes $(R=0.389$, $p=0.001$ ) bites. Other specific IgG response variations were not associated with the intensity of exposure to mosquito bites, although there was a borderline correlation between anti-PfGLURP-R0 IgG and Aedes exposure $(R=-0.228, p=0.06)$. 


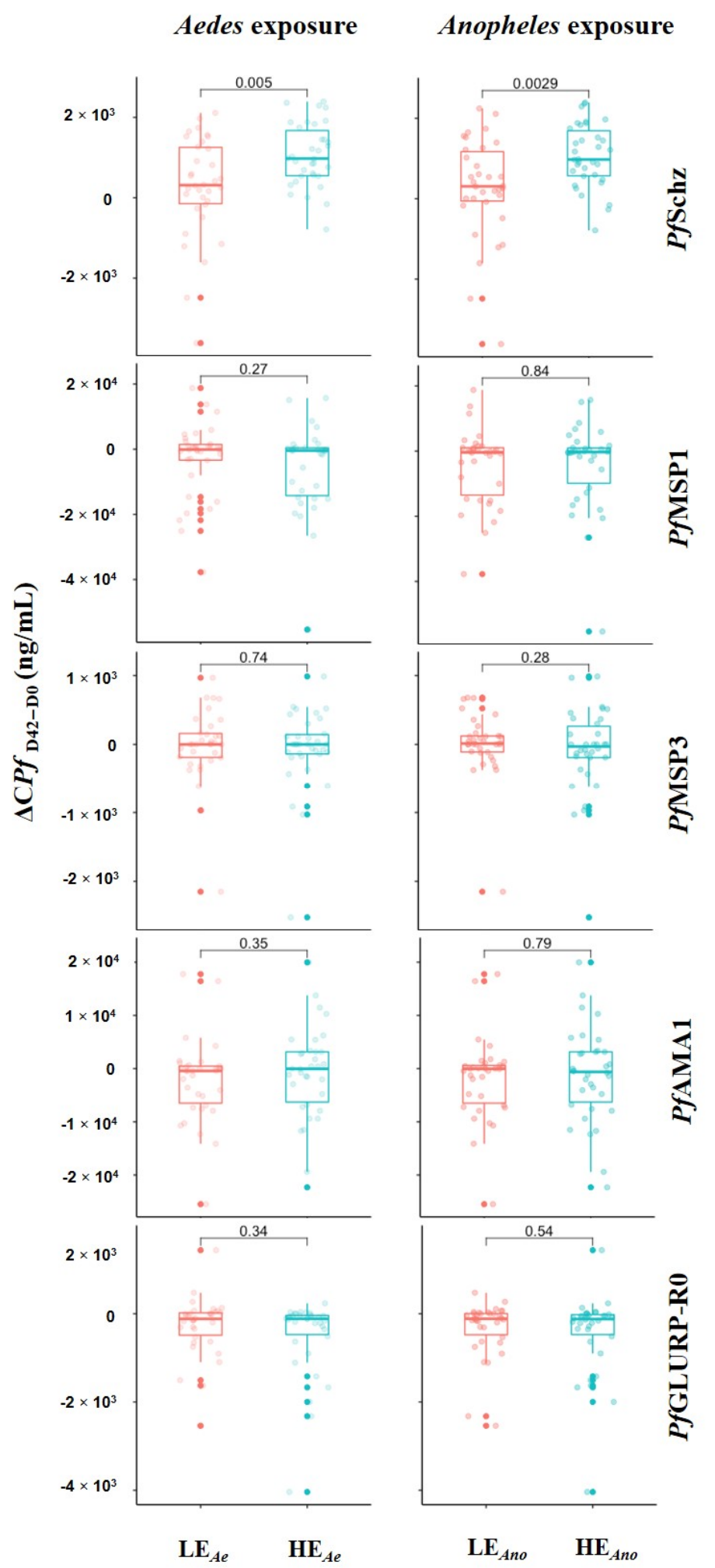

Figure 1. Variation in concentration of IgG response to P. falciparum antigens according to group of exposure to Anopheles and to Aedes (single-genus exposure). Participants were grouped according to their level of IgG response to Anopheles (lower exposure (LEAno) $<\Delta$ ODgSG6-P1 $=1.41<$ higher -exposure (HEAno)) and to Aedes (lower exposure (LEAe) $<\Delta$ ODNterm-34 kDa $=1.10<$ higher exposure (HEAe)) salivary peptide. Each dot represents an individual, and box plots indicate the median values, 25 th and 75 th percentile antibody concentration for each $P$. falciparum blood-stage antigen. Statistically significant difference in median value between the two groups is indicated (Mann-Whitney U test). 

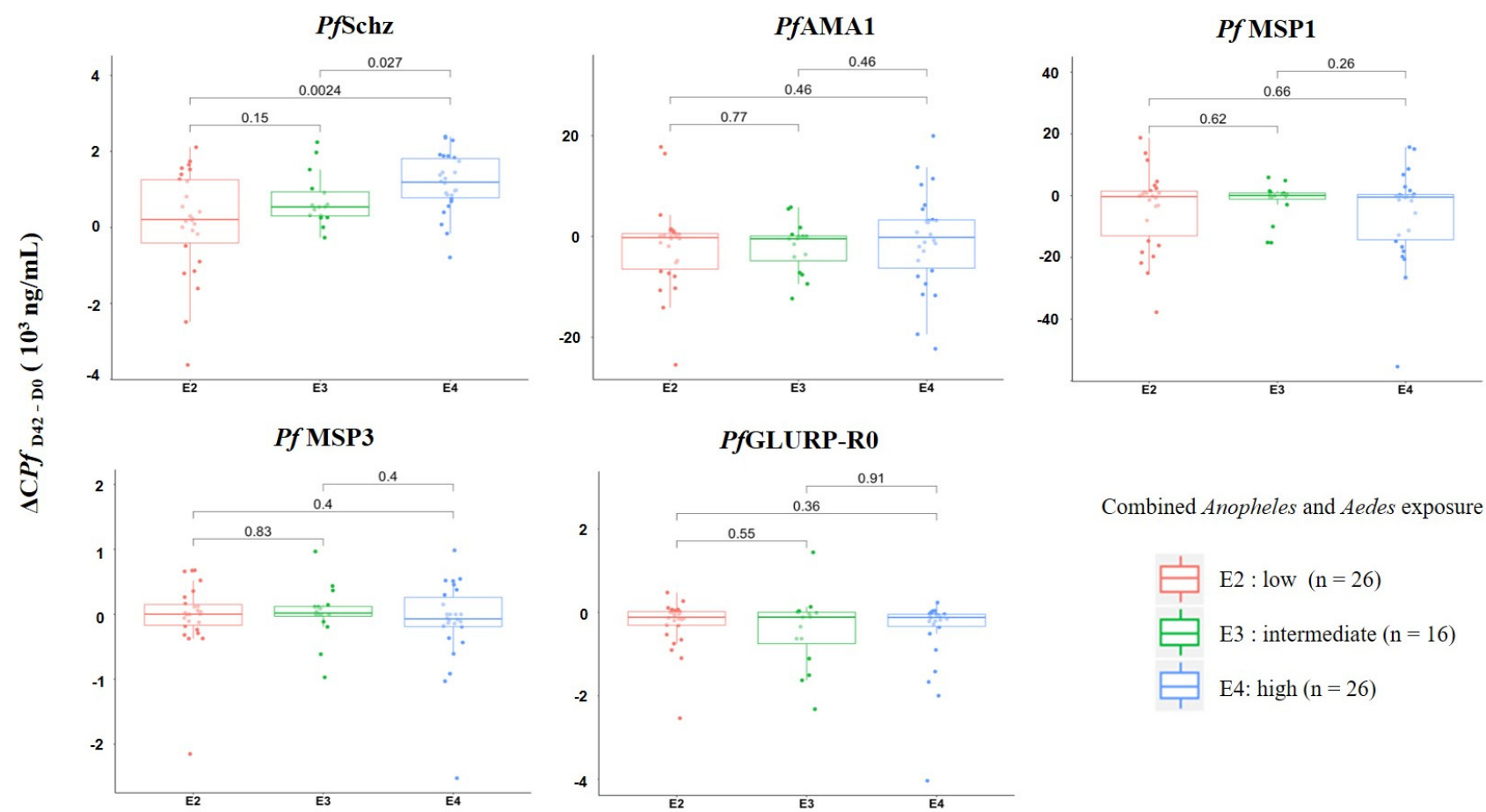

Combined Anopheles and Aedes exposure

E2 : low $(n=26)$

E3 : intermediate $(n=16)$

E4: high $(n=26)$

Figure 2. Variation in concentration of IgG response to P. falciparum antigens according to group of exposure to Anopheles and to Aedes (combined exposure). Each dot represents an individual, and box plots indicate the median value, 25th and 75th percentile antibody concentration for each blood-stage antigen. Individuals were divided into three groups (E2, E3, E4) where E2 includes individuals with lower exposure to both Anopheles and Aedes, E4 includes individuals with higher exposure to both Anopheles and Aedes, and E3 includes individuals with weak exposure to one mosquito genus and high exposure to the other. Statistically significant difference in median value between two groups is indicated (Mann-Whitney U test).

Table 2. Influence of covariates on the dynamics of IgG antibody levels to various Plasmodium and mosquito salivary antigens.

\begin{tabular}{|c|c|c|c|}
\hline Covariate Factors & Antigens & $\Delta \mathrm{CP} f_{\mathrm{D} 42-\mathrm{D} 0}(\mathrm{ng} / \mathrm{mL})$ & $p$ Value \\
\hline \multirow{5}{*}{ Gender (female/male) ${ }^{a}$} & PfSchz & $968.6(178.2 ; 1544) / 561.3(92.68 ; 1213)$ & 0.250 \\
\hline & PfAMA1 & $-1151(-6045 ; 525.5) / 413.2(-9406 ; 3340)$ & 0.322 \\
\hline & PfMSP1 & $-480.2(-14,723 ; 1322) /-267(-3129 ; 442.8)$ & 0.744 \\
\hline & PfMSP3 & $0(-165.8 ; 154.5) / 0(-181.5 ; 300.1)$ & 0.970 \\
\hline & PfGLURP-R0 & $-109.6(-349.6 ; 17.33) /-118.8(-750.8 ; 0)$ & 0.408 \\
\hline \multirow{5}{*}{ Age (years) ${ }^{b}$} & PfSchz & 0.240 & 0.049 \\
\hline & PfAMA1 & -0.013 & 0.051 \\
\hline & PfMSP1 & -0.208 & 0.088 \\
\hline & PfMSP3 & 0.055 & 0.653 \\
\hline & PfGLURP-R0 & -0.162 & 0.186 \\
\hline \multirow{5}{*}{ Weight $(\mathrm{kg})^{\mathrm{b}}$} & PfSchz & 0.252 & 0.037 \\
\hline & PfAMA1 & 0.405 & 0.006 \\
\hline & PfMSP1 & -0.128 & 0.298 \\
\hline & PfMSP3 & 0.084 & 0.495 \\
\hline & PfGLURP-R0 & -0.173 & 0.158 \\
\hline \multirow{5}{*}{ Hemoglobin (D42) ${ }^{b}$} & PfSchz & -0.123 & 0.330 \\
\hline & PfAMA1 & -0.125 & 0.317 \\
\hline & PfMSP1 & -0.112 & 0.273 \\
\hline & PfMSP3 & -0.141 & 0.261 \\
\hline & PfGLURP-R0 & -0.344 & 0.061 \\
\hline
\end{tabular}


Table 2. Cont.

\begin{tabular}{|c|c|c|c|}
\hline Covariate Factors & Antigens & $\Delta \mathrm{CPf} \mathrm{D} 42-\mathrm{D} 0(\mathrm{ng} / \mathrm{mL})$ & $p$ Value \\
\hline \multirow{5}{*}{ Treatment (ASAQ/AL) ${ }^{a}$} & PfSchz & $725.2(178.2 ; 1544) / 704.3(92.68 ; 1213)$ & 0.840 \\
\hline & PfAMA1 & $-224.0(-6045 ; 525.5) /-793.9(-9406 ; 3340)$ & 0.888 \\
\hline & PfMSP1 & $-414.6(-14,723 ; 1322) /-237.0(-3129 ; 442.8)$ & 0.577 \\
\hline & Pf MSP3 & $-100.2(-165.8 ; 154.5) / 20.53(-181.5 ; 300.1)$ & 0.021 \\
\hline & PfGLURP-R0 & $-152.7(-349.6 ; 17.33) /-92.63(-750.8 ; 0)$ & 0.535 \\
\hline \multirow{5}{*}{ Parasite density on $\mathrm{D} 0^{b}$} & PfSchz & 0.176 & 0.149 \\
\hline & PfAMA1 & 0.096 & 0.433 \\
\hline & PfMSP1 & 0.050 & 0.692 \\
\hline & PfMSP3 & 0.053 & 0.670 \\
\hline & PfGLURP-R0 & 0.036 & 0.768 \\
\hline \multirow{5}{*}{$\begin{array}{l}\text { IgG concentration on D0 } \\
(\mathrm{ng} / \mathrm{mL})^{\mathrm{b}}\end{array}$} & PfSchz & -0.361 & 0.002 \\
\hline & PfAMA1 & -0.360 & 0.002 \\
\hline & PfMSP1 & -0.625 & $<0.001$ \\
\hline & PfMSP3 & -0.540 & $<0.001$ \\
\hline & PfGLURP-R0 & -0.851 & $<0.001$ \\
\hline \multirow{5}{*}{$\begin{array}{l}\text { anti-gSG6-P1 IgG } \\
\text { b(Anopheles exposure) }\end{array}$} & PfSchz & 0.405 & $<0.001$ \\
\hline & PfAMA1 & -0.069 & 0.574 \\
\hline & PfMSP1 & -0.043 & 0.727 \\
\hline & PfMSP3 & -0.060 & 0.623 \\
\hline & PfGLURP-R0 & -0.129 & 0.294 \\
\hline \multirow{5}{*}{$\begin{array}{l}\text { anti Nterm-34 kDaIgG } \\
\text { b(Aedes exposure) }\end{array}$} & PfSchz & 0.389 & 0.001 \\
\hline & PfAMA1 & 0.055 & 0.652 \\
\hline & PfMSP1 & -0.164 & 0.180 \\
\hline & PfMSP3 & -0.140 & 0.251 \\
\hline & PfGLURP-R0 & -0.228 & 0.060 \\
\hline
\end{tabular}

a: Median (25th; 75th percentile) of variation of IgG to P. falciparum antigens during the follow-up. ${ }^{\text {b: }}$ Spearman's rho.

\subsection{Multivariate Analysis: Final Models}

To further understand the contribution of each factor (confounding variables) to the evolution of anti-PfSchz and anti-PfGLURP-R0 IgG responses, multivariate analyses were carried out, and the final models are shown in Table 3. Multivariate analyses showed a positive and significant relationship between age and variation in IgG response to PfSchz and PfGLURP-R0, while no relationships were noted for weight. The level of P. falciparum parasite density on D0 was only associated with an increase in anti-PfSchz IgG level. The models also showed that the variation in IgG responses to PfSchz and PfGLURP-R0 was strongly and negatively correlated with the pre-existing IgG level at D0 $(p<0.01)$. Individuals with higher specific IgG levels at the time of inclusion had lower levels on D42. Interestingly, a strong association was detected between the level of exposure to Aedes bites and the variation in anti-PfSchz $(p<0.001)$ and anti-PfGLURP-R0 $(p<0.05) \operatorname{IgG}$ response, while Anopheles exposure was not found to be associated with the evolution of IgG response to $P$. falciparum antigens. 
Table 3. Results of multivariate analysis indicating factors associated with variation in IgG responses to $P$. falciparum antigens during the follow-up.

\begin{tabular}{|c|c|c|c|c|c|c|c|c|c|}
\hline \multicolumn{5}{|c|}{ Variation in Anti-PfSchz IgG } & \multicolumn{5}{|c|}{ Variation in Anti-PfGLURP-R0 IgG } \\
\hline Variables & $\beta 1$ & $\begin{array}{l}\text { Sd } \\
\text { Error }\end{array}$ & $\begin{array}{c}p \\
\text { Value }\end{array}$ & $R^{2}$ & Variables & $\beta 1$ & $\begin{array}{l}\text { Sd } \\
\text { Error }\end{array}$ & $\begin{array}{c}p \\
\text { Value }\end{array}$ & $R^{2}$ \\
\hline & & & & 0.60 & & & & & 0.81 \\
\hline Age & 49.30 & 16.32 & $<0.01$ & & Age & 29.723 & 7.566 & $<0.01$ & \\
\hline Weight & - & - & - & & Weight & - & - & - & \\
\hline Parasite density on D0 & 0.004 & 0.001 & $<0.001$ & & Hemoglobin & - & - & - & \\
\hline $\begin{array}{l}\text { Anti-PfSchzIgG on D0 } \\
(\mathrm{ng} / \mathrm{mL})\end{array}$ & -0.753 & 0.100 & $<0.001$ & & $\begin{array}{l}\text { Anti-PfGLURP-R0 IgG } \\
\text { on D0 (ng } / \mathrm{mL})\end{array}$ & -0.806 & 0.049 & $<0.01$ & \\
\hline Anti-Nterm-34 kDa IgG & 1185 & 277.3 & $<0.001$ & & Anti-Nterm-34 kDa IgG & -276.11 & 132.261 & $<0.05$ & \\
\hline Anti-gSG6-P1 IgG & - & - & - & & & & & & \\
\hline
\end{tabular}

\section{Discussion}

In the present study, we described the variation in anti-Plasmodium IgG responses from study inclusion (D0) to the end of follow-up (D42) in relation to factors that might influence the kinetics of specific $\mathrm{Ab}$ responses. To exclude the antigenic boost of a P. falciparum infection on the immune responses examined, only individuals who were not re-infected were included in the final analysis. Multivariate analysis showed that age, parasite density (only for schizont extracts), anti-Plasmodium IgG response on the day of malaria diagnosis, and exposure to Aedes saliva were significantly associated with the variation in antiPlasmodium IgG responses.

At the time of inclusion, a high inter-individual variability in IgG responses was observed for PfAMA1, Pf MSP1, and PfSchz antigens, while a lower level and range of IgG responses were seen for the other antigens, highlighting the difference in immunogenicity against Plasmodium antigens [35]. During the 6-week follow-up period, the evolution of the prevalence and median values of IgG specific to $P$. falciparum differed depending on the merozoite antigens. We observed a significant increase in $\mathrm{IgG}$ responses to the schizont extract and a significant decrease in anti-PfGLURP-R0 IgG responses, while similar levels of IgG responses were noted for the other merozoite antigens. Longitudinal immunological studies have reported that following a clinical malaria infection, the specific IgG responses peak approximately 1-2 weeks after infection and then generally decline rapidly because of the short-lived duration of natural IgG responses to merozoite antigens [10-13,54,55]. It has also been shown that IgG Ab responses have a different half-life depending on the antigens [56], and this could contribute to the differences in the dynamics of immune responses to the various Plasmodium antigens observed during the follow-up. Parasite- and host-related or environmental factors may also play a role, in addition to intrinsic antibody half-life, in the modulation of the IgG response to P. falciparum over time.

We used an innovative serological assessment method to define a proxy of human exposure to Anopheles and Aedes bites at the individual level for each participant. This approach takes into account the individual heterogeneity of exposure to mosquitoes. Indeed, environmental factors generating hot spots of exposure (e.g., proximity to breeding sites), the attraction an individual exerts on mosquitoes, and the use of personal protection against mosquito bites (nets, coils, etc.) suggest that exposure to mosquito bites is highly variable from house to house and also between people living in the same house. The relevance of the gSG6-P1 and Nterm-34 kDa biomarker for epidemiological studies has been validated in various settings $[37,40,41,57,58]$. At the two time points of the followup, all of the participants had specific IgG to salivary peptides, indicating that they had all been exposed to Anopheles and Aedes bites before and during the follow-up, with an inter-individual heterogeneity in intensity of responses. According to their individual anti-gSG6-P1 and anti-Nterm-34 kDa IgG levels, individuals were separated into different groups of exposure according to a single-genus exposure and to combined exposure. 
Assuming that anti-salivary peptide IgG responses are transient and wane within a few weeks without new exposure [53,59], evaluating the exposure on D42 may reflect exposure since study initiation.

We first compared the dynamics of IgG titers against P. falciparum antigens between the different exposure groups both at the single-genus and at the combined-exposure level. We noted a positive association between the evolution of IgG responses to whole schizont extract and the intensity of exposure to Culicidae bites. Individuals with a higher exposure to Anopheles or Aedes (considered at the single-exposure level), as well as taken together (combined exposure), had a significantly increased IgG response to PfSchz during the 6-week follow-up. The evolution of IgG responses to merozoite antigens did not seem to be modulated by the intensity of mosquito exposure.

The contribution of immunomodulatory components of mosquito saliva in the variation of anti-PfSchz and anti-PfGLURP-R0 IgG responses was then assessed using univariate analysis complete with multivariate models taking into account other co-factors. Among the different factors selected, gender, weight, hemoglobin concentration, and ACT treatment were not significantly associated with variations in IgG response to PfSchz and to PfGLURP-R0 during the follow-up.

The evolution of IgG responses to PfSchz and to PfGLURP-R0 had a strong positive association with the age of the individual. Indeed, in general, antibody levels increase with both age and higher transmission intensity $[60,61]$. History of infection and cumulative malaria exposure may contribute to the inter-individual differences in the dynamics of immune responses [15]. Older individuals may have experienced more malaria infections and thus may have developed more memory B cells that will rapidly proliferate upon reinfection and differentiate into long-lived antibody-secreting cells that may last longer and induce a greater magnitude and longevity of IgG response to antigens $[10,13]$. Nevertheless, in the present study, most participants were under 10 years old, thus limiting the comparison with older people, and therefore, further investigations are needed. The parasite density at the time of diagnosis was significantly positively associated with the evolution of IgG response to schizont extracts. It can be expected that a higher parasite load will induce a greater immune response to Plasmodium parasites [12]. Interestingly, the initial level of IgG response to Plasmodium merozoite antigens (PfSchz, PfGLURP-R0) at the time of diagnosis was negatively associated with the variation in immune responses during the follow-up. This result indicates that participants with higher levels of Abs at the time of diagnosis might produce lower levels of IgG specific to Plasmodium. In malaria infection, natural regulatory $\mathrm{T}$ cells and positive/negative regulators have been shown to play a role in balancing immune responses to maintain vertebrate defense and immune balance. Plasmodium exploits regulatory mechanisms to prevent the development of adaptive immunity by enhancing negative regulators and/or inhibiting positive regulators including reduced T-cell proliferative responses to Plasmodium antigens and production of immunosuppressive IL-10 [62]. Negative regulators such as BTLA have been reported to dampen innate and T-/B-cell-mediated immune response to malaria infection $[63,64]$. However, antibodies measured at inclusion (D0) might have been acquired during previous infections but also by the current one. Indeed, there is obviously a delay between the infection and onset of symptoms, and then the visit to a health center, during which immune responses to Plasmodium are mounted.

The exposure to Aedes bites was associated with the evolution of IgG response to PfSchz and PfGLURP-R0, while Anopheles exposure was not found to modulate antiPlasmodium immunity in the 6-week follow-up period. It is increasingly recognized that the immune modulatory properties of mosquito saliva act both on the innate and adaptive immune responses of the vertebrate host, but only a few studies have assessed the consequences of Plasmodium immune responses in a natural population $[14,32,33,65]$. These studies investigated the immune relationship within a homologous malaria context (Anopheles-Plasmodium), while in the present study, we observed different anti-Plasmodium immunity modulation according to the mosquito genus with a significant effect of Aedes exposure. 
Immunomodulatory properties of mosquito saliva on the specific immune responses to heterologous antigens have also been observed in murine studies [21,31]. Previous work indicated that Culicidae saliva has different immunomodulatory effects on the vertebrate immune system depending on the mosquito genus. Wanasen et al. suggested that the production of both Th1 and Th2 cytokines was reduced in the presence of salivary gland extract from Aedes aegypti, but not from Culex quinquefasciatus [22]. Mosquito saliva is known to contain close to 100 secretory proteins, and comparative analyses indicated that some salivary proteins are ubiquitous in various genera and/or species, while others are species or genus specific $[66,67]$. This suggests that mosquito saliva from various mosquito species should have common effects as well as genus- or species-specific immunomodulatory effects. Here, compared with Anopheles saliva, the immunomodulatory activities of Aedes saliva on anti-Plasmodium immunity seemed to be more pronounced. Aedes saliva has been investigated extensively and studies reported a profound effect on lymphocyte and macrophage activity $[68,69]$. In the present study, we showed that Aedes exposure was negatively associated with the anti-PfGLURP-R0 immune response, whereas it was positively associated with the anti-PfSchz IgG response. The epidemiological observation for the down-regulated IgG response to PfGLURP-R0 in individuals with higher exposure is consistent with previous studies that reported a down-regulated immune response to a specific antigen in hosts exposed to arthropod saliva compared with naive vertebrate hosts $[21,32,33]$. Schizonts comprise a set of antigens with varying immunogenicity, while PfGLURP-R0 is a unique antigen at the surface of infected erythrocytes. A schizont may thus activate a higher number of immune cells (memory B cells or long-lived plasma cells), which may obviously result in a stronger IgG response that may last longer.

There are several important limitations of this study. First, the number and average age of the participants were low, limiting the statistical power of our analyses and limiting the comparison with immune response evolution in older individuals. The 42-day followup was too short to study the decrease in the IgG response after Plasmodium infection. We observed that most individuals exhibited very little variation in their IgG responses to certain merozoite antigens between D0 and D42. The peak of the immune response occurs approximately 2 weeks after infection and then gradually wanes. The 42-day follow-up may be the time when the level of immune response returns to its level at the time of inclusion. A more intensive and long-term sampling would be needed to track the decrease in Abs more accurately over a longer period; furthermore, the study should ideally assess the asymptomatic re-infection by Plasmodium during follow-up, which might cause a boost in immune responses.

The present work is the first to report that exposure to Aedes saliva may contribute, in addition to other factors, to the regulation of anti-Plasmodium immune responses. Additional studies are needed to characterize separately the effects of saliva of different blood-feeding arthropods on the human immune system, by analyzing ex vivo cytokine production after stimulation of peripheral blood mononuclear cells. The immunomodulatory properties of mosquito saliva and their consequences for malaria transmission need further investigation and may contribute to a better understanding of the human-vectorparasite immune relationships.

Author Contributions: Conceptualization, F.R. and A.P.; Formal analysis, K.G.A.; Funding acquisition, A.A.K., C.R. and F.R.; Investigation, K.G.A., S.S.Y. and E.A.G.; Methodology, K.G.A., F.R. and A.P.; Resources, A.M.A., S.B.A. and O.A.T.; Supervision, V.C. and A.P.; Visualization, K.G.A. and A.P.; Writing-original draft, K.G.A. and A.P.; Writing-review and editing, V.C., C.R., F.R. and A.P. All authors have read and agreed to the published version of the manuscript.

Funding: This research was funded by the French Initiative $5 \%$ and Expertise France, Grant $\mathrm{N}^{\circ} 12$ INI210. K.G. Aka was supported by a PhD fellowship provided by the Institut Hospitalo-Universitaire (IHU) Méditerranée Infection Foundation, Marseille, France. 
Institutional Review Board Statement: The study was conducted according to the guidelines of the Declaration of Helsinki, and approved by the Ethics Committee of the Ministry of Health of Côte d'Ivoire (June 2015; No. 029/MSLS/CNER-dkn).

Informed Consent Statement: Written informed consent of all parents or guardians of children who participated in the study was obtained before inclusion and any sample collection.

Data Availability Statement: The dataset analyzed during the current study is available from the last author on reasonable request.

Acknowledgments: We gratefully acknowledge the populations of Dar-es-Salam neighborhood (Bouaké), especially participants and health workers for their kind support and collaboration. We kindly thank S. Longagre (Vaximax, France) for providing the PfMSP1p19 recombinant protein, E.J. Remarque (Biomedical Primate Research Centre, Rijswijk, The Netherlands) for the PfAMA1 recombinant protein, and Michael Theisen (Statens Serum Institut, Copenhagen, Denmark) for the PfGLURP-R0 and PfMSP3 recombinant proteins. We would also like to especially thank Isabella Athanassiou (Bonn, Germany) for language editing.

Conflicts of Interest: The authors declare no conflict of interest. The funders had no role in the design of the study; in the collection, analyses, or interpretation of data; in the writing of the manuscript, or in the decision to publish the results.

\section{References}

1. Sabchareon, A.; Burnouf, T.; Ouattara, D.; Attanath, P.; Bouharoun-Tayoun, H.; Chantavanich, P.; Foucault, C.; Chongsuphajaisiddhi, T.; Druilhe, P. Parasitologic and Clinical Human Response to Immunoglobulin Administration in Falciparum Malaria. Am. J. Trop. Med. Hyg. 1991, 45, 297-308. [CrossRef] [PubMed]

2. Cohen, S.; McGREGOR, I.A.; Carrington, S. Gamma-Globulin and Acquired Immunity to Human Malaria. Nature 1961, 192, 733-737. [CrossRef] [PubMed]

3. Stanisic, D.I.; Fowkes, F.J.I.; Koinari, M.; Javati, S.; Lin, E.; Kiniboro, B.; Richards, J.S.; Robinson, L.J.; Schofield, L.; Kazura, J.W.; et al. Acquisition of Antibodies against Plasmodium Falciparum Merozoites and Malaria Immunity in Young Children and the Influence of Age, Force of Infection, and Magnitude of Response. Infect. Immun. 2015, 83, 646-660. [CrossRef] [PubMed]

4. Akpogheneta, O.J.; Dunyo, S.; Pinder, M.; Conway, D.J. Boosting Antibody Responses to Plasmodium Falciparum Merozoite Antigens in Children with Highly Seasonal Exposure to Infection. Parasite Immunol. 2010, 32, 296-304. [CrossRef] [PubMed]

5. Wang, Q.; Zhao, Z.; Zhang, X.; Li, X.; Zhu, M.; Li, P.; Yang, Z.; Wang, Y.; Yan, G.; Shang, H.; et al. Naturally Acquired Antibody Responses to Plasmodium Vivax and Plasmodium Falciparum Merozoite Surface Protein 1 (MSP1) C-Terminal 19 KDa Domains in an Area of Unstable Malaria Transmission in Southeast Asia. PLoS ONE 2016, 11, e0151900. [CrossRef]

6. Murungi, L.M.; Kamuyu, G.; Lowe, B.; Bejon, P.; Theisen, M.; Kinyanjui, S.M.; Marsh, K.; Osier, F.H.A. A Threshold Concentration of Anti-Merozoite Antibodies Is Required for Protection from Clinical Episodes of Malaria. Vaccine 2013, 31, 3936-3942. [CrossRef] [PubMed]

7. Roussilhon, C.; Oeuvray, C.; Müller-Graf, C.; Tall, A.; Rogier, C.; Trape, J.-F.; Theisen, M.; Balde, A.; Pérignon, J.-L.; Druilhe, P. Long-Term Clinical Protection from Falciparum Malaria Is Strongly Associated with IgG3 Antibodies to Merozoite Surface Protein 3. PLoS Med. 2007, 4, e320. [CrossRef] [PubMed]

8. Courtin, D.; Oesterholt, M.; Huismans, H.; Kusi, K.; Milet, J.; Badaut, C.; Gaye, O.; Roeffen, W.; Remarque, E.J.; Sauerwein, R.; et al. The Quantity and Quality of African Children's IgG Responses to Merozoite Surface Antigens Reflect Protection against Plasmodium Falciparum Malaria. PLoS ONE 2009, 4, e7590. [CrossRef]

9. Reiling, L.; Boyle, M.J.; White, M.T.; Wilson, D.W.; Feng, G.; Weaver, R.; Opi, D.H.; Persson, K.E.M.; Richards, J.S.; Siba, P.M.; et al. Targets of Complement-Fixing Antibodies in Protective Immunity against Malaria in Children. Nat. Commun. 2019, 10, 610. [CrossRef]

10. Yman, V.; White, M.T.; Asghar, M.; Sundling, C.; Sondén, K.; Draper, S.J.; Osier, F.H.A.; Färnert, A. Antibody Responses to Merozoite Antigens after Natural Plasmodium Falciparum Infection: Kinetics and Longevity in Absence of Re-Exposure. BMC Med. 2019, 17, 22. [CrossRef]

11. Kinyanjui, S.M.; Conway, D.J.; Lanar, D.E.; Marsh, K. IgG Antibody Responses to Plasmodium Falciparum Merozoite Antigens in Kenyan Children Have a Short Half-Life. Malar J. 2007, 6, 82. [CrossRef] [PubMed]

12. Proietti, C.; Verra, F.; Bretscher, M.T.; Stone, W.; Kanoi, B.N.; Balikagala, B.; Egwang, T.G.; Corran, P.; Ronca, R.; Arcà, B.; et al. Influence of Infection on Malaria-Specific Antibody Dynamics in a Cohort Exposed to Intense Malaria Transmission in Northern Uganda. Parasite Immunol. 2013, 35, 164-173. [CrossRef] [PubMed]

13. Akpogheneta, O.J.; Duah, N.O.; Tetteh, K.K.A.; Dunyo, S.; Lanar, D.E.; Pinder, M.; Conway, D.J. Duration of Naturally Acquired Antibody Responses to Blood-Stage Plasmodium Falciparum Is Age Dependent and Antigen Specific. Infect. Immun. 2008, 76, 1748-1755. [CrossRef] [PubMed] 
14. Dechavanne, C.; Sadissou, I.; Bouraima, A.; Ahouangninou, C.; Amoussa, R.; Milet, J.; Moutairou, K.; Massougbodji, A.; Theisen, M.; Remarque, E.J.; et al. Acquisition of Natural Humoral Immunity to P. Falciparum in Early Life in Benin: Impact of Clinical, Environmental and Host Factors. Sci. Rep. 2016, 6, 33961. [CrossRef] [PubMed]

15. Gonçalves, R.M.; Lima, N.F.; Ferreira, M.U. Parasite Virulence, Co-Infections and Cytokine Balance in Malaria. Pathog. Glob. Health 2014, 108, 173-178. [CrossRef]

16. Fillol, F.; Sarr, J.B.; Boulanger, D.; Cisse, B.; Sokhna, C.; Riveau, G.; Simondon, K.B.; Remoué, F. Impact of Child Malnutrition on the Specific Anti-Plasmodium Falciparum Antibody Response. Malar. J. 2009, 8, 116. [CrossRef]

17. Hogh, B.; Petersen, E.; Crandall, I.; Gottschau, A.; Sherman, I.W. Immune Responses to Band 3 Neoantigens on Plasmodium Falciparum-Infected Erythrocytes in Subjects Living in an Area of Intense Malaria Transmission Are Associated with Low Parasite Density and High Hematocrit Value. Infect. Immun. 1994, 62, 4362-4366. [CrossRef]

18. Ter Horst, R.; Jaeger, M.; Smeekens, S.P.; Oosting, M.; Swertz, M.A.; Li, Y.; Kumar, V.; Diavatopoulos, D.A.; Jansen, A.F.M.; Lemmers, H.; et al. Host and Environmental Factors Influencing Individual Human Cytokine Responses. Cell 2016, 167, 1111-1124.e13. [CrossRef]

19. Ribeiro, J.M. Role of Saliva in Blood-Feeding by Arthropods. Annu. Rev. Entomol. 1987, 32, 463-478. [CrossRef]

20. Fontaine, A.; Diouf, I.; Bakkali, N.; Missé, D.; Pagès, F.; Fusai, T.; Rogier, C.; Almeras, L. Implication of Haematophagous Arthropod Salivary Proteins in Host-Vector Interactions. Parasit Vectors 2011, 4, 187. [CrossRef]

21. Depinay, N.; Hacini, F.; Beghdadi, W.; Peronet, R.; Mécheri, S. Mast Cell-Dependent down-Regulation of Antigen-Specific Immune Responses by Mosquito Bites. J. Immunol. 2006, 176, 4141-4146. [CrossRef]

22. Wanasen, N.; Nussenzveig, R.H.; Champagne, D.E.; Soong, L.; Higgs, S. Differential Modulation of Murine Host Immune Response by Salivary Gland Extracts from the Mosquitoes Aedes Aegypti and Culex Quinquefasciatus. Med. Vet. Entomol. 2004, 18, 191-199. [CrossRef]

23. Schneider, B.S.; Soong, L.; Zeidner, N.S.; Higgs, S. Aedes aegypti salivary gland extract modulate anti-viral and TH1/TH2 cytokine responses to sindbis virus infection. Viral. Immunol. 2004, 17, 565-573. [CrossRef]

24. Schneider, B.S.; Higgs, S. The Enhancement of Arbovirus Transmission and Disease by Mosquito Saliva Is Associated with Modulation of the Host Immune Response. Trans. R. Soc. Trop. Med. Hyg. 2008, 102, 400-408. [CrossRef] [PubMed]

25. Zeidner, N.S.; Higgs, S.; Happ, C.M.; Beaty, B.J.; Miller, B.R. Mosquito Feeding Modulates Th1 and Th2 Cytokines in Flavivirus Susceptible Mice: An Effect Mimicked by Injection of Sialokinins, but Not Demonstrated in Flavivirus Resistant Mice. Parasite Immunol. 1999, 21, 35-44. [CrossRef] [PubMed]

26. Vogt, M.B.; Lahon, A.; Arya, R.P.; Kneubehl, A.R.; Spencer Clinton, J.L.; Paust, S.; Rico-Hesse, R. Mosquito Saliva Alone Has Profound Effects on the Human Immune System. PLoS Negl. Trop Dis. 2018, 12, e0006439. [CrossRef] [PubMed]

27. Demeure, C.E.; Brahimi, K.; Hacini, F.; Marchand, F.; Péronet, R.; Huerre, M.; St-Mezard, P.; Nicolas, J.-F.; Brey, P.; Delespesse, G.; et al. Anopheles Mosquito Bites Activate Cutaneous Mast Cells Leading to a Local Inflammatory Response and Lymph Node Hyperplasia. J. Immunol. 2005, 174, 3932-3940. [CrossRef] [PubMed]

28. Donovan, M.J.; Messmore, A.S.; Scrafford, D.A.; Sacks, D.L.; Kamhawi, S.; McDowell, M.A. Uninfected Mosquito Bites Confer Protection against Infection with Malaria Parasites. Infect. Immun. 2007, 75, 2523-2530. [CrossRef] [PubMed]

29. Pollock, T.; Leitao, R.; Galan-Rodriguez, C.; Wong, K.A.; Rodriguez, A. Daily Plasmodium Yoelii Infective Mosquito Bites Do Not Generate Protection or Suppress Previous Immunity against the Liver Stage. Malar J. 2011, 10, 97. [CrossRef]

30. Kebaier, C.; Voza, T.; Vanderberg, J. Neither Mosquito Saliva nor Immunity to Saliva Has a Detectable Effect on the Infectivity of Plasmodium Sporozoites Injected into Mice. Infect. Immun 2010, 78, 545-551. [CrossRef]

31. Menten-Dedoyart, C.; Couvreur, B.; Thellin, O.; Drion, P.V.; Herry, M.; Jolois, O.; Heinen, E. Influence of the Ixodes Ricinus Tick Blood-Feeding on the Antigen-Specific Antibody Response in Vivo. Vaccine 2008, 26, 6956-6964. [CrossRef]

32. Sarr, J.B.; Samb, B.; Sagna, A.B.; Fortin, S.; Doucoure, S.; Sow, C.; Senghor, S.; Gaayeb, L.; Guindo, S.; Schacht, A.-M.; et al. Differential Acquisition of Human Antibody Responses to Plasmodium Falciparum According to Intensity of Exposure to Anopheles Bites. Trans. R. Soc. Trop. Med. Hyg. 2012, 106, 460-467. [CrossRef]

33. Aka, K.G.; Traoré, D.F.; Sagna, A.B.; Zoh, D.D.; Assi, S.B.; Tchiekoi, B.N.; Adja, A.M.; Remoue, F.; Poinsignon, A. Pattern of Antibody Responses to Plasmodium Falciparum Antigens in Individuals Differentially Exposed to Anopheles Bites. Malar J. 2020, 19, 83. [CrossRef] [PubMed]

34. Ambrosino, E.; Dumoulin, C.; Orlandi-Pradines, E.; Remoue, F.; Toure-Baldé, A.; Tall, A.; Sarr, J.B.; Poinsignon, A.; Sokhna, C.; Puget, K.; et al. A Multiplex Assay for the Simultaneous Detection of Antibodies against 15 Plasmodium Falciparum and Anopheles Gambiae Saliva Antigens. Malar. J. 2010, 9, 317. [CrossRef] [PubMed]

35. Drakeley, C.J.; Corran, P.H.; Coleman, P.G.; Tongren, J.E.; McDonald, S.L.R.; Carneiro, I.; Malima, R.; Lusingu, J.; Manjurano, A.; Nkya, W.M.M.; et al. Estimating Medium- and Long-Term Trends in Malaria Transmission by Using Serological Markers of Malaria Exposure. Proc. Natl. Acad. Sci. USA 2005, 102, 5108-5113. [CrossRef] [PubMed]

36. Crompton, P.D.; Pierce, S.K.; Miller, L.H. Advances and Challenges in Malaria Vaccine Development. J. Clin. Investig. 2010, 120, 4168-4178. [CrossRef] [PubMed]

37. Sagna, A.B.; Yobo, M.C.; Elanga Ndille, E.; Remoue, F. New Immuno-Epidemiological Biomarker of Human Exposure to Aedes Vector Bites: From Concept to Applications. Trop Med. Infect. Dis. 2018, 3, 80. [CrossRef] [PubMed] 
38. Sagna, A.; Poinsignon, A.; Remoue, F. Epidemiological applications of assessing mosquito exposure in a malaria-endemic area. In Arthropod Vector: Controller of Disease Transmission; Elsevier: Amsterdam, The Netherlands, 2017; Volume 2, pp. 209-229. ISBN 978-0-12-805360-7.

39. Traoré, D.F.; Sagna, A.B.; Adja, A.M.; Zoh, D.D.; Adou, K.A.; Lingué, K.N.; Coulibaly, I.; Tchiekoi, N.B.; Assi, S.B.; Poinsignon, A.; et al. Exploring the Heterogeneity of Human Exposure to Malaria Vectors in an Urban Setting, Bouaké, Côte d'Ivoire, Using an Immuno-Epidemiological Biomarker. Malar. J. 2019, 18, 68. [CrossRef] [PubMed]

40. Sagna, A.B.; Kassié, D.; Couvray, A.; Adja, A.M.; Hermann, E.; Riveau, G.; Salem, G.; Fournet, F.; Remoue, F. Spatial Assessment of Contact between Humans and Anopheles and Aedes Mosquitoes in a Medium-Sized African Urban Setting, Using Salivary Antibody-Based Biomarkers. J. Infect. Dis. 2019, 220, 1199-1208. [CrossRef] [PubMed]

41. Traoré, D.F.; Sagna, A.B.; Adja, A.M.; Zoh, D.D.; Lingué, K.N.; Coulibaly, I.; N'Cho Tchiekoi, B.; Assi, S.B.; Poinsignon, A.; Dagnogo, M.; et al. Evaluation of Malaria Urban Risk Using an Immuno-Epidemiological Biomarker of Human Exposure to Anopheles Bites. Am. J. Trop. Med. Hyg. 2018, 98, 1353-1359. [CrossRef] [PubMed]

42. Toure, O.A.; Assi, S.B.; N’Guessan, T.L.; Adji, G.E.; Ako, A.B.; Brou, M.J.; Ehouman, M.F.; Gnamien, L.A.; Coulibaly, M.A.A.; Coulibaly, B.; et al. Open-Label, Randomized, Non-Inferiority Clinical Trial of Artesunate-Amodiaquine versus ArtemetherLumefantrine Fixed-Dose Combinations in Children and Adults with Uncomplicated Falciparum Malaria in Côte d'Ivoire. Malar. J. 2014, 13, 439. [CrossRef] [PubMed]

43. Zoh, D.D.; Yapi, A.; Adja, M.A.; Guindo-Coulibaly, N.; Kpan, D.M.S.; Sagna, A.B.; Adou, A.K.; Cornelie, S.; Brengues, C.; Poinsignon, A.; et al. Role of Anopheles Gambiae s.s. and Anopheles Coluzzii (Diptera: Culicidae) in Human Malaria Transmission in Rural Areas of Bouaké, in Côte d'Ivoire. J. Med. Entomol. 2020, 57, 1254-1261. [CrossRef] [PubMed]

44. Koffi, A.A.; Ahoua Alou, L.P.; Adja, M.A.; Chandre, F.; Pennetier, C. Insecticide Resistance Status of Anopheles Gambiae s.s Population from M’Bé: A WHOPES-Labelled Experimental Hut Station, 10 Years after the Political Crisis in Côte d'Ivoire. Malar J. 2013, 12, 151. [CrossRef] [PubMed]

45. Toure, O.A.; Landry, T.N.; Assi, S.B.; Kone, A.A.; Gbessi, E.A.; Ako, B.A.; Coulibaly, B.; Kone, B.; Ouattara, O.; Beourou, S.; et al. Malaria Parasite Clearance from Patients Following Artemisinin-Based Combination Therapy in Côte d'Ivoire. Infect. Drug Resist. 2018, 11, 2031-2038. [CrossRef] [PubMed]

46. Bonnet, S.; Pêtres, S.; Holm, I.; Fontaine, T.; Rosario, S.; Roth, C.; Longacre, S. Soluble and Glyco-Lipid Modified Baculovirus Plasmodium Falciparum C-Terminal Merozoite Surface Protein 1, Two Forms of a Leading Malaria Vaccine Candidate. Vaccine 2006, 24, 5997-6008. [CrossRef] [PubMed]

47. Faber, B.W.; Remarque, E.J.; Kocken, C.H.M.; Cheront, P.; Cingolani, D.; Xhonneux, F.; Jurado, M.; Haumont, M.; Jepsen, S.; Leroy, O.; et al. Production, Quality Control, Stability and Pharmacotoxicity of CGMP-Produced Plasmodium Falciparum AMA1 FVO Strain Ectodomain Expressed in Pichia Pastoris. Vaccine 2008, 26, 6143-6150. [CrossRef] [PubMed]

48. Theisen, M.; Vuust, J.; Gottschau, A.; Jepsen, S.; Høgh, B. Antigenicity and Immunogenicity of Recombinant Glutamate-Rich Protein of Plasmodium Falciparum Expressed in Escherichia Coli. Clin. Diagn. Lab. Immunol. 1995, 2, 30-34. [CrossRef] [PubMed]

49. Amoah, L.E.; Acquah, F.K.; Ayanful-Torgby, R.; Oppong, A.; Abankwa, J.; Obboh, E.K.; Singh, S.K.; Theisen, M. Dynamics of Anti-MSP3 and Pfs230 Antibody Responses and Multiplicity of Infection in Asymptomatic Children from Southern Ghana. Parasites Vectors 2018, 11, 13. [CrossRef]

50. Niass, O.; Saint-Pierre, P.; Niang, M.; Diop, F.; Diouf, B.; Faye, M.M.; Sarr, F.D.; Faye, J.; Diagne, N.; Sokhna, C.; et al. Modelling Dynamic Change of Malaria Transmission in Holoendemic Setting (Dielmo, Senegal) Using Longitudinal Measures of Antibody Prevalence to Plasmodium Falciparum Crude Schizonts Extract. Malar J. 2017, 16, 409. [CrossRef]

51. Elanga Ndille, E.; Doucoure, S.; Damien, G.; Mouchet, F.; Drame, P.M.; Cornelie, S.; Noukpo, H.; Yamadjako, S.; Djenontin, A.; Moiroux, N.; et al. First Attempt to Validate Human IgG Antibody Response to Nterm-34kDa Salivary Peptide as Biomarker for Evaluating Exposure to Aedes Aegypti Bites. PLoS Negl. Trop Dis. 2012, 6, e1905. [CrossRef]

52. Poinsignon, A.; Cornelie, S.; Mestres-Simon, M.; Lanfrancotti, A.; Rossignol, M.; Boulanger, D.; Cisse, B.; Sokhna, C.; Arcà, B.; Simondon, F.; et al. Novel Peptide Marker Corresponding to Salivary Protein GSG6 Potentially Identifies Exposure to Anopheles Bites. PLoS ONE 2008, 3, e2472. [CrossRef] [PubMed]

53. Drame, P.M.; Poinsignon, A.; Besnard, P.; Cornelie, S.; Le Mire, J.; Toto, J.-C.; Foumane, V.; Dos-Santos, M.A.; Sembène, M.; Fortes, F.; et al. Human Antibody Responses to the Anopheles Salivary GSG6-P1 Peptide: A Novel Tool for Evaluating the Efficacy of ITNs in Malaria Vector Control. PLoS ONE 2010, 5, e15596. [CrossRef] [PubMed]

54. Boutlis, C.S.; Fagan, P.K.; Gowda, D.C.; Lagog, M.; Mgone, C.S.; Bockarie, M.J.; Anstey, N.M. Immunoglobulin G (IgG) Responses to Plasmodium Falciparum Glycosylphosphatidylinositols Are Short-Lived and Predominantly of the IgG3 Subclass. J. Infect. Dis. 2003, 187, 862-865. [CrossRef] [PubMed]

55. Cavanagh, D.R.; Elhassan, I.M.; Roper, C.; Robinson, V.J.; Giha, H.; Holder, A.A.; Hviid, L.; Theander, T.G.; Arnot, D.E.; McBride, J.S. A Longitudinal Study of Type-Specific Antibody Responses to Plasmodium Falciparum Merozoite Surface Protein-1 in an Area of Unstable Malaria in Sudan. J. Immunol. 1998, 161, 347-359. [PubMed]

56. Fowkes, F.J.I.; McGready, R.; Cross, N.J.; Hommel, M.; Simpson, J.A.; Elliott, S.R.; Richards, J.S.; Lackovic, K.; Viladpai-Nguen, J.; Narum, D.; et al. New Insights into Acquisition, Boosting, and Longevity of Immunity to Malaria in Pregnant Women. J. Infect. Dis. 2012, 206, 1612-1621. [CrossRef] 
57. Ya-Umphan, P.; Cerqueira, D.; Parker, D.M.; Cottrell, G.; Poinsignon, A.; Remoue, F.; Brengues, C.; Chareonviriyaphap, T.; Nosten, F.; Corbel, V. Use of an Anopheles Salivary Biomarker to Assess Malaria Transmission Risk along the Thailand-Myanmar Border. J. Infect. Dis. 2017, 215, 396-404. [CrossRef]

58. Drame, P.M.; Diallo, A.; Poinsignon, A.; Boussari, O.; Dos Santos, S.; Machault, V.; Lalou, R.; Cornelie, S.; LeHesran, J.-Y.; Remoue, F. Evaluation of the Effectiveness of Malaria Vector Control Measures in Urban Settings of Dakar by a Specific Anopheles Salivary Biomarker. PLoS ONE 2013, 8, e66354. [CrossRef]

59. Doucoure, S.; Mouchet, F.; Cornelie, S.; Drame, P.M.; D’Ortenzio, E.; DeHecq, J.S.; Remoue, F. Human Antibody Response to Aedes Albopictus Salivary Proteins: A Potential Biomarker to Evaluate the Efficacy of Vector Control in an Area of Chikungunya and Dengue Virus Transmission. Biomed. Res. Int. 2014, 2014, 746509. [CrossRef]

60. King, C.L.; Davies, D.H.; Felgner, P.; Baum, E.; Jain, A.; Randall, A.; Tetteh, K.; Drakeley, C.J.; Greenhouse, B. Biosignatures of Exposure/Transmission and Immunity. Am. J. Trop Med. Hyg. 2015, 93, 16-27. [CrossRef]

61. McCallum, F.J.; Persson, K.E.M.; Fowkes, F.J.I.; Reiling, L.; Mugyenyi, C.K.; Richards, J.S.; Simpson, J.A.; Williams, T.N.; Gilson, P.R.; Hodder, A.N.; et al. Differing Rates of Antibody Acquisition to Merozoite Antigens in Malaria: Implications for Immunity and Surveillance. J. Leukoc Biol. 2017, 101, 913-925. [CrossRef]

62. Cai, C.; Hu, Z.; Yu, X. Accelerator or Brake: Immune Regulators in Malaria. Front. Cell Infect. Microbiol. $2020,10,610121$. [CrossRef] [PubMed]

63. Adler, G.; Steeg, C.; Pfeffer, K.; Murphy, T.L.; Murphy, K.M.; Langhorne, J.; Jacobs, T. B and T Lymphocyte Attenuator Restricts the Protective Immune Response against Experimental Malaria. J. Immunol. 2011, 187, 5310-5319. [CrossRef]

64. Sun, Y.; Brown, N.K.; Ruddy, M.J.; Miller, M.L.; Lee, Y.; Wang, Y.; Murphy, K.M.; Pfeffer, K.; Chen, L.; Kaye, J.; et al. B and T Lymphocyte Attenuator Tempers Early Infection Immunity. J. Immunol. 2009, 183, 1946-1951. [CrossRef] [PubMed]

65. Sarr, J.B.; Remoue, F.; Samb, B.; Dia, I.; Guindo, S.; Sow, C.; Maiga, S.; Tine, S.; Thiam, C.; Schacht, A.-M.; et al. Evaluation of Antibody Response to Plasmodium Falciparum in Children According to Exposure of Anopheles Gambiae s.l or Anopheles Funestus Vectors. Malar J. 2007, 6, 117. [CrossRef] [PubMed]

66. Calvo, E.; Sanchez-Vargas, I.; Favreau, A.J.; Barbian, K.D.; Pham, V.M.; Olson, K.E.; Ribeiro, J.M. An Insight into the Sialotranscriptome of the West Nile Mosquito Vector, Culex Tarsalis. BMC Genom. 2010, 11, 51. [CrossRef] [PubMed]

67. Ribeiro, J.M.C.; Charlab, R.; Pham, V.M.; Garfield, M.; Valenzuela, J.G. An Insight into the Salivary Transcriptome and Proteome of the Adult Female Mosquito Culex Pipiens Quinquefasciatus. Insect Biochem Mol. Biol. 2004, 34, 543-563. [CrossRef] [PubMed]

68. Barros, M.S.; Lara, P.G.; Fonseca, M.T.; Moretti, E.H.; Filgueiras, L.R.; Martins, J.O.; Capurro, M.L.; Steiner, A.A.; Sá-Nunes, A. Aedes Aegypti Saliva Impairs M1-Associated Proinflammatory Phenotype without Promoting or Affecting M2 Polarization of Murine Macrophages. Parasit Vectors 2019, 12, 239. [CrossRef] [PubMed]

69. Bizzarro, B.; Barros, M.S.; Maciel, C.; Gueroni, D.I.; Lino, C.N.; Campopiano, J.; Kotsyfakis, M.; Amarante-Mendes, G.P.; Calvo, E.; Capurro, M.L.; et al. Effects of Aedes Aegypti Salivary Components on Dendritic Cell and Lymphocyte Biology. Parasit Vectors 2013, 6, 329. [CrossRef] [PubMed] 